\title{
Community Policing: Reinventing the Wheel?
}

\author{
Robert R. Friedmann*
}

\begin{abstract}
Georgia International Law Enforcement Exchange, Andrew Young School of Policy Studies, Georgia State University, P. O. Box 3987, Atlanta, GA 30302-3987, USA
\end{abstract}

\begin{abstract}
Community Policing (CP) has been a much used, overused and abused term. Many blindly adopt it, others blindly reject it. This brief article argues that a cogent policing strategy that deploys CP should start with the focus on the epidemiology of crime and the understanding of how crime is produced. There is no need to reinvent the wheel of policing strategies. Just drive it.
\end{abstract}

Keywords: Community Policing, Homeland Security, IACP, Proactive Policing, Reactive Policing.

Community Policing (CP) emerged in the mid-1980s as a new policing strategy. Unlike many public policies that are formulated by politicians (with at least some based on scientific data-driven proposals), CP - at least in the U.S. - emerged from a group of inspired police leaders, frustrated with the revolving-door impact of traditional reactive policing. These leaders were looking for more effective approaches to deal with soaring crime figures. U.S. policing was encouraged and influenced by policing advances made particularly in the U.K. and in Canada. The Clinton administration gave $\mathrm{CP}$ its public visibility with a commitment to add 100,000 officers across the U.S. (a target not reached; according to NIJ figures it fell short by 15 to 31 percent) and particularly committing to budgets in the form of federal grants for $\mathrm{CP}$ initiatives. The focus on homeland security following the September 11, 2001 atrocity, has essentially replaced CP as the prevalent public safety approach that was also backed up by generous budgets, grants, and a huge governmental administrative enterprise.

Time and space preclude an in-depth delineation of the complexities of CP but suffice it to say that the strength of CP also carries with it its greatest weakness. Namely, it is a nebulous and sometimes misunderstood concept that is often in the eyes of the beholder. It relies on an "understanding" of what it is or what it should be but all too often it appears that there are many and different "understandings" ranging from the very tactical to the very strategic. It is perhaps less shocking to realize if we consider that laws vary significantly from state to state (not to mention country to country) and so do legal definitions of crime (and punishment). Thus, one might hear a police chief

*Address correspondence to this author at the Georgia International Law Enforcement Exchange, Andrew Young School of Policy Studies, Georgia State University, P. O. Box 3987, Atlanta, GA 30302-3987, USA; Tel: 404-4131025; E-mail: friedmann@gsu.edu arguing that "we have always done community policing," making a reference to police practices from the 19th century, that CP is "not a real crime fighting approach", that "the budget is not allowing for the practice of community policing," or that "we are committed to community policing."

The problem with these statements is reflective of the very concept's nebulousness: "always doing community policing" implies developing good relations with the community and that alone does not constitute $\mathrm{CP}$; claiming that $\mathrm{CP}$ is "not a real crime fighting approach" illustrates the rejection of the concept but even more so the misunderstanding of what policing is about; so does the statement that "the budget is insufficient" to practice CP. No less troubling is the apparent "winner" statement of "commitment to CP." This is where the nebulousness of the concept is most apparent: what does commitment mean? Namely, who is committed? Is it the chief? Is it the command staff? Is it a single officer? Is it a unit? Is it the entire department? Is it the governing body and the community? How is this commitment measured? Namely, what metrics do we have to know that CP is being practiced? Is there a CP deployment, communication, evaluation, and a reward mechanism? Is the deployment done department-wide or is it limited to a unit? Is it limited to internal police procedures and tactics or are outside partners involved? Who are the partners? How effective is the partnership? What is the extent of "buy-in" on the part of key partners such as municipal and county leaders, other department heads, the community, and civic associations? With such questions having potentially many different answers, or no answers, it is not surprising to find criticism of CP, some which is rather violent as in "let's kill it and move on" (Shults 2011). Whether it is false acceptance of CP (from concept to implementation) on one hand, or the non-valid criticism of it (rejection) on the other - both miss what $\mathrm{CP}$ is. 
For the last 15 years the International Association of Chiefs of Police (IACP) Community Policing Committee (CPC) has recognized police departments with awards of excellence for best CP practices. See the list of awards (1998-2012) and, in a more detailed fashion the list for the later period (2009-2012). The CPC is active in the award selection process and in furthering $\mathrm{CP}$ as the ideal practice for modern policing. It is therefore doubly sobering to realize that in some of the committee's discussions the nebulousness of CP (re)surfaces from time to time. The committee offers (in a video format) an bverview of CP, a review of the rramework questions (for the award application), a review of the nitiatives questions, a review of the initiative evaluations, and a review of the essons earned. These reviews are probably the most cogent, concise, and helpful documentations for police practitioners.

Yet, it appears that from time to time a "refresher" reminder may be called for. CP is not simply about being friendly, about developing community relations, or even about forging partnerships. After all, it is imperative that judges who evaluate, rank and reward (or reject) applications do so in a consistently reliable and valid manner which behooves them to have a common understanding of what $\mathrm{CP}$ is. If the understanding of $\mathrm{CP}$ is limited to these superficial dimensions, a department is simply missing an opportunity to do far more and far better than concentrating its efforts on public relations. This focuses on tactics but not on strategy. It is therefore helpful to put CP in some context and perhaps to start with what it is NOT. CP is not reactive policing. It is about being proactive. That is a markedly different approach from the reactive policing practiced until the mid-1980s (and continues to date). CP is not a substitute for reactive policing but rather a supplement to it. Emergency reaction is needed when it is appropriate. However, management-by-emergency may not have an impact on the overall production of crime, or what ends up being viewed as official crime statistics. Reactive and proactive policing should be deployed to improve service to the public in the interest of public safety. In the same way that preventive fire procedures and preventive health measures play an important role in fire safety policy and public health policy, so should proactive measures play a key role in combatting crime and do so before it occurs.

At the early days of CP there were two sets of working assumptions that guided the approach police departments were expected to adopt. The first was offered by John Alderson (1979) and the second by Trojanowicz and Bucqueroux (1990). Alderson's ten principles related to policing under conditions of freedom with emphasis on guaranteeing personal freedom and free passage and movement of people and merchandise. The ten principles offered by Trojanowicz and Bucqueroux have more to do with the implementation of the concept in a given police force. Yet in most communities the shift to community policing was characterized by introducing (or re-introducing) foot-patrol and the beat officer returning to the neighborhood. The field actually lacked a definition of CP. Taking CP for granted - in a misperceived or insufficient way - raises the prospects that the concept would simply be abused; and thus become devoid of any practical service value. Hence a definition of $\mathrm{CP}$ should assist in fully understanding its scope.

Viewing $\mathrm{CP}$ as a policing strategy - and not merely as a tactic - Friedmann (1992) offered the first definition of $\mathrm{CP}$ in the professional literature:

Community policing is a policy and a
strategy aimed at achieving more effective
and efficient crime control, reduced fear of
crime, improved quality of life, improved
police services and police legitimacy,
through a proactive reliance on community
resources that seeks to change crime
causing conditions. This assumes a need
for greater accountability of police, greater
public share in decision making, and
greater concern for civil rights and
liberties.

A more concise delineation of this definition of $\mathrm{CP}$ and the environment in which it is to be practiced focuses on internal and external factors that impact the functioning of police (Friedmann 1996).

Friedmann $(1992,1996)$ views CP not only from the legal approach to crime but also from a behavioral approach. The legal approach denotes crime as a violation of the law. The behavioral approach denotes crime as a resolution of a conflict (albeit in an illegal way). In other words, if crime is viewed as an epidemic (and it is) it needs to be viewed from an epidemiological approach. Hence, the reactive approach is rather limited in scope and it focuses on crime after it occurs and it does not drill down into the causes behind it that result in the production of crime. The proactive approach helps understand what makes crime occur and therefore offers a strategy to reduce crime production. 
This analytical approach has consequences for any policy formulation by providing guidelines such as: what problem to focus on, how to deploy forces, who to partner with, and how to minimize the production of crime. Tactics such as intelligence-led policing and hotspot analysis have proactive elements but CP offers the overarching strategy that attempts to understand not only who might commit crimes, where, and when, but also, WHY. In other words, CP adds an explanatory dimension to the predictive one offered by other popular methods. It is exactly the focus on the WHY that can help devise means to curb the production of crime and thus prevent crime in an attempt to minimize it.

The same way that the correct medical intervention requires and relies on a correct diagnosis, correct policing intervention requires a better understanding of why crime takes place, by whom, when, where and under what conditions. Not only by a certain perpetrator against a certain victim but also in consideration of the types of social, political, economic and other factors such crime occurs. In other words, CP is not only there to develop various techniques that make it attractive (at least to those who say they adapted (P), or popular, but to actually make a difference in the amount of crime and fear of crime. Police leaders are well-advised to look at what influences the production of crime in their jurisdictions and once developing an understanding of the factors involved then they can employ the relevant CP tactics of proactive partnership development and institute the required internal and external organizational changes and do so within an overarching policing strategy in concert with many other stakeholders outside the police.

As emergency room service has little impact on the epidemiology of diseases, providing emergency police response has limited value in impacting overall crime production and the known figures of crime. While homeland security (HS) has been in the forefront of governmental policy and budget allocation since 2001, there is a growing realization that $\mathrm{CP}$ and $\mathrm{HS}$ have a great deal in common (Friedmann and Cannon 2007). It is gratifying to know that the interest in the commonality between $\mathrm{CP}$ and HS is growing and that this article had one of the top criminal justice and criminology downloads recently. It is also gratifying to see the increased level of attendance of the membership of the IACP CPC and the attendance in its professional gatherings. It gives hope and encouragement that a focused strategy on (minimizing) the production of crime can also help lead to its very reduction. That is the real value of CP. There is no need to reinvent the wheel. Just use it to steer your department in the most effective direction.

\section{REFERENCES}

Alderson, John C. 1979. Policing Freedom: A Commentary on the Dilemmas of Policing in Western Democracies.Braintree, MA: MacDonald and Evans.

Friedmann,Robert R. 1992. Community Policing: Comparative Perspectives and Prospects.New York: St. Martin's Press.

Friedmann, Robert R. 1996. "Community Policing: Some Conceptual and Practical Considerations," Home Affairs Review, 34(6): 114-23. (in Hungarian). English version: http://www.cjgsu.net/initiatives/considerations.htm

Friedmann, Robert R. and William J. Cannon. 2007. "Homeland Security and Community Policing: Competing or Complementing Public Safety Policies," Journal of Homeland Security and Emergency Management: 4(4) http://www.cigsu.net/initiatives/HS-ICJR.pdf http://dx.doi.org/10.2202/1547-7355.1371

Shults, Joel F. 2011. "What Did 'Community Policing' Teach Us? If 'Community Policing' Isn't Already Dead, Let's Kill It and Move On." Policeone.com

http://www.policeone.com/columnists/JoelShults/articles/4537819-IACP-2011-Whatdid-communitypolicing-teach-us/

Trojanowicz, Robert and Bonnie Bucqueroux. 1990. Community Policing: A Contemporary Perspective. Cincinnati, $\mathrm{OH}$ : Anderson.

Received on 17-07-2013

Accepted on 31-07-2013

Published on 13-08-2013

\section{DOI: http://dx.doi.org/10.6000/1929-4409.2013.02.27}

(C) 2013 Robert R. Friedmann; Licensee Lifescience Global.

This is an open access article licensed under the terms of the Creative Commons Attribution Non-Commercial License (http://creativecommons.org/licenses/by-nc/3.0/) which permits unrestricted, non-commercial use, distribution and reproduction in any medium, provided the work is properly cited. 